\title{
CARBOIDRATOS DE PLANTAS FORRAGEIRAS PARA RUMINANTES: UMA REVISÃO
}

\author{
SILVA, Alex Lopes da ${ }^{1}$ \\ SOUSA, Dalva Batista de ${ }^{2}$ \\ AMORIM, Diego Sousa ${ }^{3}$ \\ SANTOS, Marilania da Silva ${ }^{1}$ \\ SILVA, Kleitiane Balduino da ${ }^{1}$ \\ NASCIMENTO, Romilda Rodrigues do ${ }^{4}$
}

RESUMO: Os carboidratos correspondem a 50-80\% da matéria seca das plantas forrageiras, estes são compostos formados por carbono, hidrogênio e oxigênio. As forragens são a base da alimentação dos ruminantes, a qual fornece nutrientes para o desempenho animal. Isso propõe que seja realizado estudos que disponibilize dados que favoreça o correto manejo alimentar. Os métodos de composição permitem a determinação de carboidratos totais, além disso surge a opção destes serem fracionados e classificados, como fração A: açúcares solúveis com rápida degradação ruminal, B1: amido e pectina, B2: correspondente à fibra potencialmente degradável com taxa de degradação mais lenta e C: que apresenta característica de indigestibilidade. O total de carboidratos não estrutural é uma estimativa de energia prontamente disponível para os microrganismos ruminais, já os fibrosos lhes confere o bom funcionamento do rúmen. Objetivou-se obter informações das determinações dos carboidratos de plantas forrageiras utilizadas na alimentação de ruminantes.

Palavras-chave: Alimentação. Metodologia. Produção animal.

\section{CARBOHYDRATES OF FORAGE PLANTS FOR RUMINANTS: A REVIEW}

\begin{abstract}
SUMMARY: The carbohydrates correspond to $50-80 \%$ of the dry matter of fodder plants, these are compounds formed by carbon, hydrogen and oxygen. Fodder is the basis of ruminant feed, which provides nutrients for animal performance. This proposes to carry out studies that provide data that favors correct food management. The methods of composition allow the determination of total carbohydrates, in addition the option to fractionate and classify them as fraction A: soluble sugars with rapid ruminal degradation, B1: starch and pectin, B2: corresponding to the potentially degradable fiber with degradation rate and $\mathrm{C}$ : which has an indigestibility characteristic. Non-structural carbohydrate total is an estimate of energy readily available for ruminal microorganisms, while the fibrous ones give them good rumen function. The objective of this study was to obtain information on the carbohydrate determinations of forage plants used in ruminant feeding.
\end{abstract}

Keywords: Feeding. Methodology. Animal production.

\section{INTRODUÇÃO}

O Atendimento das exigências nutricionais de ruminantes requer significativamente do conteúdo de energia e proteína da dieta (VIANA et al., 2012). Neste contexto, o uso eficiente de

\footnotetext{
${ }^{1}$ Departamento de Zootecnia, Universidade Federal da Paraíba, Centro de Ciências Agrarias, Campus II, Areia Paraíba.

${ }^{2}$ Engenheira Agrônoma

${ }^{3}$ Departamento de Zootecnia, Universidade Federal do Ceará, Campus do PICI, Fortaleza - Ceará.

${ }^{4}$ Departamento de Ciência Animal, Universidade Federal de Campina Grande, Campus de Patos, Patos - Paraíba.
} 
carboidratos na fração de biomassa produzida, exige muita atenção (WANG et al., 2017) e depende do seu valor nutricional e qualidade, os quais são determinados por complexa interação entre os nutrientes ingeridos e a ação dos microrganismos no trato digestório, nos processos de digestão, absorção, transporte e utilização de metabólitos, não esquecendo da condição fisiológica do animal (PEREIRA et al., 2010).

Os carboidratos são compostos formados por carbono, hidrogênio e oxigênio que representam a categoria mais abundante em termos de nutrientes nas plantas. São usados nos processos de crescimento de plantas, regulação osmótica e metabolismo secundário (HURA et al., 2016). Importante frisar que as plantas apresentam diferenças estruturais e morfológicas, além de uma ampla variedade de nichos ecológicos aos herbívoros de modo que eles venham a pastejarem (VAN SOEST, 1994).

Os carboidratos constituem $50-80 \%$ da matéria seca de forragens e cereais e fisiologicamente classificam-se em: (a) açúcares simples e seus conjugados ativos no metabolismo intermediário das plantas; (b) compostos de reserva ou armazenamento (amido, sacarose e frutanas); e (c) polissacarídeos estruturais, principalmente pectinas, hemiceluloses e celulose que são geralmente irrecuperáveis (VAN SOEST, 1994).

Os carboidratos estruturais fazem parte da parede celular das plantas, constituídos por celulose, hemicelulose e pectina e considerados a principal fonte de energia nas dietas de ruminantes (AGODA-TANDJAWA et al., 2012; MEDEIROS et al., 2015). A celulose é o homopolissacarídeo mais abundante na natureza. Sua macromolécula é composta por unidades de monómero de D-glicose ligadas entre si através de ligações -1-4-glicosídicas. A hemicelulose é o segundo polissacarídeo principal na célula vegetal. São heteropolímeros, ou seja, compostos de diferentes unidades monoméricas. Já a pectina é um polissacarídeo péctico, um polímero de carboidratos altamente complexo e heterogêneo (NEGAHDAR et al., 2016). A pectina, mesmo sendo um carboidrato estrutural, é praticamente toda utilizada no rúmen, no entanto, a hemicelulose tem a degradabilidade ruminal entre $45-90 \%$ e a celulose, entre $25-90 \%$ (MEDEIROS et al., 2015).

Objetivou-se com esta revisão obter informações de determinações dos carboidratos de plantas forrageiras utilizadas na alimentação de ruminantes.

\section{IMPORTÂNCIA DOS CARBOIDRATOS PARA RUMINANTES}

As avaliações de plantas forrageiras dispõem grande valor prático na alimentação de ruminantes (DETMANN et al., 2009). Pois, a pastagem compõe a base da dieta dos sistemas de produção da pecuária brasileira (CAVALCANTI et al., 2016). Sendo os carboidratos (CHO) os 
mais abundante em termos nutricionais nas plantas (MEDEIROS et al., 2015). E após serem consumidas pelos ruminantes, os microrganismos ruminais degradam principalmente carboidratos estruturais, simultaneamente os não estruturais, transformando-os em açúcares simples e ácidos graxos de cadeia curta (SINGH et al., 2012; MEDEIROS et al., 2015). Contudo, o tipo e a quantidade dos carboidratos influenciam a fermentação e eficiência microbiana (VAN SOEST et al., 1991).

Os carboidratos fibrosos auxilia na manutenção do $\mathrm{pH}$ ruminal por estimular a ruminação e produção de saliva (OLIVEIRA et al., 2016). Entretanto, permiti resistência a digestibilidade e reduz a síntese de proteína microbiana além de ter baixa taxa de fermentação (SILVA e NEUMANN, 2012; OLIVEIRA et al., 2016). Ocasionando lenta taxa de passagem rúmenreticulo reduzindo a ingestão de matéria seca total, comprometendo o desempenho do animal (ALVES et al., 2016).

Carboidratos não fibrosos, são de rápida degradação ruminal e tem maior aporte energético para o desenvolvimento dos microrganismos ruminais (ROMÃO et al., 2013). São os principais substratos para fermentação dos microrganismos ruminais (NTAIKOU et al., 2008). Podem ter influência negativa no rúmen, podendo levar um desequilíbrio do pH (OLIVEIRA et al., 2016; ALVES et al., 2016).

\section{DETERMINAÇÃO DE CARBOIDRATOS EM PLANTAS FORRAGEIRAS}

A determinação dos carboidratos pode ser obtida pela extração inicial dos teores de proteína bruta $(\mathrm{PB})$, extrato etéreo $(\mathrm{EE})$, matéria mineral $(\mathrm{MM})$, fibra em detergente neutro (FDN), FDN corrigida para cinzas e proteína (FDNcp), lignina e proteína insolúvel em detergente neutro (PIDN) expressos em percentagem da matéria seca, pois esses compostos são utilizados nas equações (MS) (AOAC 1990; VAN SOEST et al.,1991; SILVA e QUEIROZ 2005).

As metodologias de composição permitem a determinação da percentagem de carboidratos totais (CT) que pode ser estimado por diferença da percentagem de proteína bruta (\%PB), extrato etéreo (\%EE) e cinzas (\%cinza), como segue a equação proposta por Sniffen et al. (1992): $\mathrm{CT}=100-(\% \mathrm{~PB}+\% \mathrm{EE}+\%$ cinza $)$, alguns resultados batidos presente na tabela 1. Já para obter carboidratos não fibrosos (CNF), necessita teor de fibra em detergente neutro (FDN) corrigido para cinzas e proteínas e assim ser estimado o CNF segundo recomendações de Mertens (2002), descrito por Sniffen et al. (1992): CNF = $100-(\% \mathrm{~PB}+\% \mathrm{EE}+\% \mathrm{FDNcp}+\%$ Cinzas $)$. Porém, os carboidratos não estruturais $(\mathrm{CNE})$ podem ser obtidos pela equação $\mathrm{CNE}=100$ $[($ FDNPIDN $)+$ PB + EE + MM] descrita por Stokes et al. (1991). 
Tabela 1. Teores de carboidratos totais (\% na matéria seca).

\begin{tabular}{lcccc}
\hline \multicolumn{1}{c}{ Planta } & & Carboidratos & Autor \\
\cline { 1 - 2 } Nome científico & Nome comum & Totais & \\
\cline { 1 - 2 } Prosopis juliflora & Algaroba & 71,86 & \\
Pithecellobium multiflorum & Canafístula & 76,93 & Pereira et al. $(2010)$ \\
Senna obtusifolia & Mata-pasto & 63,80 & \\
\hline Leucaena leucocephala & Leucena & 85,6 & \multirow{2}{*}{ Singh et al. $(2012)$} \\
Sorghum bicolor & Sorgo & 64,8 & \\
\hline Pennisetum purpureum & Capim Elefante & $78,0 *$ & Ribeiro et al. $(2014)$ \\
\hline Saccharum officinarum & Cana-de-açúcar & $90,9 *$ & Riguerira et al. (2017) \\
\hline Urochloa decumbens & Brachiarinha & 75,55 & Strada et al. (2019) \\
\hline
\end{tabular}

* Dados expresso com base na matéria natural

Fonte: Adaptado de Pereira et al. (2010); Singh et al. (2012); Ribeiro et al. (2014); Riguerira et al. (2017) e Strada et al. (2019)

Outra metodologia utilizada é por meio de espectroscopia de reflectância infravermelha próxima (NIRS). Este procedimento envolve a combinação de um espectrofotômetro de reflectância infravermelha com um computador programado, onde nesta determinação o sistema escaneia o espectro infravermelho de um alimento e correlaciona os espectros resultantes com aqueles das amostras padrões de conhecida composição que também foram escaneados pelo sistema, neste momento o computador calcula a composição química das amostras desconhecidas para que a entrada de dados e os padrões sejam comparados (VAN SOEST, 1994). Saliba et al. (2003) utilizando o método de NIRS na determinação da composição química de sorgo, obtiveram 15,1\% de carboidratos solúveis, com um coeficiente de determinação de 98,7\%. Dessa forma, pode ser recomendado para uso em experimentação animal (ALMEIDA et al., 2018).

Existem situações em que métodos podem ser adaptados e comparados com metodologias consagradas, caso obtenham resultados coerentes e viável, torna-se uma opção para analises. Um exemplo é o estudo de Ibáñez e Bauer (2014), que estudando método reduzido usando filtros de microfibra de vidro para a determinação de lignina e carboidratos estruturais de palha de milho (Zea mays ssp.) e bagaço da cana-de-açúcar (Saccharum officinarum) com amostras a partir de um método reduzido $(50 \mathrm{mg})$ e pequena escala $(5 \mathrm{mg})$ em filtros de microfibras de vidro adaptado de Sluiter et al. (2012), que é um método convencional (300 mg) em que utiliza cadinhos cerâmicos, após comparação, concluíram que o método é altamente reprodutível e é capaz de refletir a composição da biomassa com suficiente precisão. 


\section{FRACIONAMENTO DOS CARBOIDRATOS}

O conhecimento da digestibilidade dos nutrientes que compõem os alimentos das dietas dos ruminantes é de extrema importância na produção animal (PEREIRA et al., 2010). E o fracionamento permite um entendimento, não só ao aproveitamento dos animais, mais também para as plantas. Silva e Queiroz (2005) pois, o total de carboidratos não estrutural é uma estimativa de energia prontamente disponível para a planta. Porém, o crescimento e desenvolvimento da parede celular das plantas podem ser divididos em fases, permitindo o desenvolvimento da parede primária com alongamento celular e deposição de pectina, xilanas e celulose, e quando cessa o alongamento celular, ocorre o espessamento da parede secundária, fase na qual a lignina passa a ser depositada mais intensamente (DETMANN et al., 2009).

Os carboidratos totais podem ser fracionados e classificados, como fração (A) açúcares solúveis com rápida degradação ruminal, (B1) amido e pectina, (B2) correspondente à fibra potencialmente degradável com taxa de degradação mais lenta e $(\mathrm{C})$ que apresenta característica de indigestibilidade (SNIFFEN et al., 1992) obtidos após a digestão in vitro de 72 horas, ou após 144 horas de incubação in situ Cabral et al. (2004). Assim as frações podem ser obtidas conforme as equações proposta por Sniffen et al. (1992):

Frações com elevadas taxas de degradação ruminal $(\mathrm{A}+\mathrm{B} 1)$ :

$$
100-(\mathrm{C}+\mathrm{B} 2)
$$

A fração B2 obtida pela equação:

$$
\begin{gathered}
\mathrm{B} 2=100 *[(\mathrm{FDN}(\% \mathrm{MS})-\mathrm{PIDN}(\% \mathrm{~PB}) * 0,01 \mathrm{~PB}(\% \mathrm{MS}))-(\mathrm{FDN}(\% \mathrm{MS}) * 0,01 * \\
\operatorname{Lignina}(\% \mathrm{FDN}) * 2,4)] / \mathrm{CT}(\% \mathrm{MS}) \mathrm{e}
\end{gathered}
$$

A fração C:

$$
\mathrm{C}=100 * \mathrm{FDN}(\% \mathrm{MS}) * 0,01 *(\operatorname{Lignina}(\% \mathrm{FDN}) * 2,4) / \mathrm{CT}(\% \mathrm{MS}) .
$$

Estas podem ser aplicadas tanto para as determinações das frações das forrageiras in natura quanto em silagens. Viana et al. (2012) trabalhando com fracionamento de carboidratos e de proteína das silagens de diferentes forrageiras (Tabela 2), onde a fração C foi estimada pela FDN indigestível após 144 horas de incubação in situ, verificaram que os CT variaram de 59,5 a 80,7 . 
Tabela 2. Teores percentuais médios de carboidratos totais (CT), carboidratos não fibrosos (A + B1), componentes disponíveis correspondentes à fração potencialmente degradável (B2), fração indigestível da parede celular (C) de silagens de milho, sorgo forrageiro e girassol.

\begin{tabular}{lcccc}
\hline \multirow{2}{*}{ Item } & \multicolumn{4}{c}{ Silagens } \\
\cline { 2 - 5 } & Milho & Sorgo forrageiro & Girassol & CV \% \\
\hline Carboidratos totais (\%MS) & $80,7 \mathrm{a}$ & $77,8 \mathrm{a}$ & $59,5 \mathrm{~b}$ & 2,3 \\
Fração A + B1 (\%CT) & $32,2 \mathrm{~b}$ & $19,9 \mathrm{c}$ & $37,8 \mathrm{a}$ & 10,2 \\
Fração B2 (\%CT) & $42,0 \mathrm{a}$ & $40,7 \mathrm{a}$ & $26,8 \mathrm{~b}$ & 12,0 \\
Fração C (\%CT) & $25,8 \mathrm{c}$ & $39,3 \mathrm{a}$ & $35,5 \mathrm{ab}$ & 9,9 \\
\hline
\end{tabular}

Fonte: Adaptado de Viana et al. (2012).

Notas: Médias seguidas da mesma letra na linha não diferem estatisticamente a $5 \%$ pelo teste Tukey.

CV - Coeficiente de variação $(\%)$.

Viana et al. (2012) afirmam que a superioridade dos CT da silagem do milho e do sorgo forrageiro são devido a menores teores de proteína bruta 8,6 e 4,0\% e extrato etéreo 9,1 e 3,5\% respectivamente, em relação ao girassol $12,1 \%$ de $\mathrm{PB}$ e $13,6 \%$ de EE. O amido presente nos grãos de girassol contribuiu para o aumento da fração $A+B 1$ das silagens e os valore mais elevados da fração B2 para silagens de milho e sorgo forrageiro silagens deve-se, principalmente, à maior contribuição de colmo nas plantas de sorgo e espigas no milho e os teores da fração C podem ter sido influenciados pelos teores de lignina com base na matéria seca das silagens de milho (3,5\%) sorgo (4,9\%) e girassol (7,0\%). Segundo Medeiros et al., (2015), os CNE (A+B1) são rapidamente fermentados pelos microrganismos ruminais, e assim são fontes prontamente disponíveis de energia para o meio ruminal.

Pereira et al. (2010) ao fracionar os carboidratos da Algaroba (Prosopis juliflora), Canafístula (Pithecellobium multiflorum), Flor-de-seda (Calotropis procera), Jitirana (Ipomea sp.), Juazeiro (Ziyiphus joazeiro), Mata-pasto (Senna obtusifolia), Sabiá (Mimosa caesalpiniifolia), Palma gigante (Opuntia fícus indica) e Xique-xique (Cereus gounellei), observam que a Canafístula e o Juazeiro apresentaram os maiores valores para a fração C (40,40 e 40,63\%, respectivamente) e valores de fração A+B1 (35,26 e 30,91\%, respectivamente) e fração B2 (24,34 e 28,45\%, respectivamente), já o Mata-pasto e a Palma gigante apresentaram os menores valores para fração C (17,34 e 22,76\%, respectivamente).

Fração C constitui de proteína associada com lignina e complexos tanino-proteína, estes geralmente não são degradados no rúmen (KRISHNAMOORTHY et al., 1982). Quando a hemicelulose encontra-se associada à lignina através de ligações covalentes, torna-se indisponível à solubilização (MACEDO JÚNIOR et al., 2007; OLIVEIRA et al., 2016). Zikeli et al. (2016) em estudo com fracionamento e caracterização de lignina de palha de trigo, através de isolamento 
de lignina e complexos de lignina-carboidrato, obteve $70 \%$ da lignina total recuperada como intimamente ligada a carboidrato.

O estado fenológico permite variações na composição devido a lignificação e senescência dos tecidos, dessa forma, os carboidratos podem variar entre espécies ou idade (CAVALCANTI et al., 2016). Neste contexto, as frações podem variar com o avanço da idade das forrageiras. Sá et al. (2010), em seu estudo com fracionamento de carboidratos de gramíneas tropicais cortadas em três idades (28, 35 e 54 dias), encontraram interação entre gramíneas versus idade. Os autores obtiveram efeito linear decrescente $(P<0,05)$ para fração A + B1 com base na \% nitrogênio total (NT) do Tifton 85 com 22,1, 18,2 e 16,5\% NT, Marandu com 25,5, 25,0 e 19,7\% NT e Tanzânia que teve $24,2,21,2$ e 20,5\% NT com avanço da idade (28, 35 e 54 dias) e a fração B2 o Tifton 85 com 41,5, 45,6 e 44,9\% NT e Marandu com 34,8 e 36,6 e 44,6 de \% NT apresentaram comportamento linear crescente, já o Tanzânia obteve comportamento inverso 35,7, 35,3 e 34,6 em \% NT. Para fração C, todos tiveram efeito linear crescente o Tifton 85 com 11,0, 13,4 e 21,3 \%NT, Marandu com 11,8, 12,9 e 17,2\% NT e Tanzânia com 12,9 19,6 e 26,3\% NT nas idades de corte, o que pode ser atribuído ao aumento na fração de hemicelulose e celulose indigestível da parede celular.

O fracionamento permite uma visão da qualidade dos carboidratos presentes nas plantas forrageiras, norteando se os teores são o suficiente para atender a demanda dos ruminantes.

\section{TÉCNICA DE PRODUÇÃO DE GASES}

Nesta técnica, a digestão in vitro produz uma mistura de gases, e a pressão formada pelo acúmulo dos gases, que inicialmente é medida em unidades elétricas $(\mathrm{mV})$, pode ser convertida em volume de gás (mL), assim as taxas de rápida digestão CNF e de lenta digestão dos CF podem ser estimadas. Nesta determinação os equipamentos do sistema incluem uma incubadora com um agitador, sensores de pressão conectados aos frascos de incubação, um cartão analógico digital conversor e um computador com software (PELL; SCHOFIELD, 1993).

As curvas acumulativa da produção de gases é analisada empregando-se um modelo logístico bicompartimental, que permite a estimação de: volume máximo de gás produzido pela degradação da fração solúvel de rápida digestão $\left(V f_{1}\right)$; taxa específica de produção de gás pela degradação da fração solúvel de rápida digestão $\left(k_{l}\right)$; taxa específica de produção de gás pela degradação da fracção insolúvel potencialmente degradável de digestão lenta $\left(k_{2}\right)$; volume máximo de gás produzido pela degradação da fracção insolúvel potencialmente degradável de digestão lenta $\left(V f_{2}\right)$ e latência ( $L$ ) (SCHOFIELD et al., 1994). 
Conforme a metodologia descrita acima, Detmann et al. (2009) estudando a cinética da degradação ruminal dos carboidratos fibrosos dos capins Setária (Setaria anceps), Hemarthria (Hemarthria altissima), Angola (Urochloa purpurascens) e Acroceres (Acroceras macrum) em diferentes idades de corte (28, 42, 56 e 70 dias) e doses de adubação nitrogenada (0, 100, 200, 300 e 400 de $\mathrm{N} \mathrm{ha}^{-1}$ ) obtiveram médias de fração $V f_{l}$ variando para Setária com 10,04 a 11,79 mL, Hemarthria de 9,18 a 10,64 mL, Angola com 8,83 a 14,86 mL e Acroceres de 14,18 a 15,54 $\mathrm{mL}$, para $k_{1}$ : o Setária com 0,0142 a 0,0172 mL, Hemarthria de 0,0103 a 0,0142 mL, Angola de 0,0112 a $0,0133 \mathrm{~mL}$ e Acroceres com 0,0126 a $0,0133 \mathrm{~mL}$, a fração $k_{2}$ : o Setária com 0,0658 a 0,0753 mL, Hemarthria de 0,0392 a 0,0667 mL, Angola entre 0,0602 a 0,0895 mL e Acroceres com 0,0753 a $0,0936 \mathrm{~mL}$, já para $V f_{2}$ : o Setária ficou entre 8,56 a 11,73 mL, Hemarthria de 7,93 a 10,26 mL, Angola com 3,97 a 7,93 mL e Acroceres de 4,93 a 5,96 mL. Os autores concluíram que os parâmetros da cinética de degradação ruminal dos carboidratos das forrageiras foram influenciados pelas idades de corte.

Peretti et al. (2017) em estudo com Aveia branca (Avena sativa L.) cv. IPR126 sob diferentes níveis de nitrogênio $\left(0,180,360\right.$ e $720 \mathrm{~kg} \mathrm{ha}^{-1}$ de $\left.\mathrm{N}\right)$ utilizando a metodologia de Schofield et al. (1994), verificaram frações de carboidratos com volume de gás para $V f_{l}$ com $13,02,13,54,13,07,12,79 \mathrm{~mL}$ respectivamente, na fração $k_{1}$ todos os tratamentos obtiveram 0,09 $\mathrm{mL}$ e $k_{2}$ o tratamento controle (0) com $0,03 \mathrm{~mL}$ e os demais tratamentos com $0,02 \mathrm{~mL}$, já $V f_{2}$ observaram $13,86,12,22,12,27$ e $12,67 \mathrm{~mL}$ e a latência $(L)$ com $0,56,0,80,1,06$ e $0,81 \mathrm{~mL}$ para doses $0,180,360$ e 720 respectivamente. Conforme os autores, os resultados obtidos demostram que não há necessidade a adição de nitrogênio a Aveia branca.

\section{DETERMINAÇÃO DE CARBOIDRATOS SOLÚVEIS}

A estimação de carboidratos solúveis pode ser obtida por determinações laboratoriais com utilização de reagentes, conforme metodologias de Silva e Queiroz (2005), onde a determinação de carboidratos (amilose, mono e dissacarídeos) constitui-se em deixar amostras em contato com oxalato de amônio, em ebulição, por duas horas e, após a hidrolise, os monossacarídeos resultantes glicose são determinados calorimetricamente pela reação de cor com o reagente antrona.

Conforme Oliveira et al. (2016), a parede celular pode ser separada dos conteúdos celulares. Neste contexto, obtém-se também a partição de carboidratos solúveis em detergente neutro (CSDN), desenvolvido por Hall et al. (1999) partido em ácido orgânico, açúcar, amido e frações fibrosas solúveis, obtidos através de extração com $80 \%$ de etanol, separando açúcares e ácidos orgânicos de baixo peso molecular dos polissacarídeos (amido e fibra solúvel), onde 
açúcares são medidos diretamente no extrato de etanol, já o amido é por meio do resíduo insolúvel em etanol. Ácidos orgânicos e CSDN são obtidas de acordo as frações propostas pelos autores:

$$
\begin{aligned}
& \mathrm{AO}=(\mathrm{MO}-\mathrm{PB})-(\mathrm{MOIE}-\mathrm{PBIE})-\mathrm{EE}-\mathrm{Açúcares} \\
& \mathrm{CSDN}=(\mathrm{MOIE}-\mathrm{PBIE}) \text { - (MORDN - PBRDN }) \text { - AIE, onde: }
\end{aligned}
$$

$\mathrm{AO}=$ Ácido orgânicos, $\mathrm{MO}=$ matéria orgânica, $\mathrm{PB}=$ proteína bruta, $\mathrm{MOIE}=$ matéria orgânica insolúvel em etanol a $80 \%$, PBIE = proteína bruta insolúvel em etanol a $80 \%$, EE = extrato etéreo; $\mathrm{CSDN}$ = carboidratos solúveis em detergente neutro, $\mathrm{MORDN}=$ matéria orgânica no resíduo de detergente neutro, PBRDN = proteína bruta insolúvel no resíduo de detergente neutro e AIE = amido insolúvel em etanol a $80 \%$.

Também podem ser utilizado o método do ácido sulfúrico concentrado descrito por Dubois et al. (1956) com adaptações de Corsato et al. (2008) em que construiu-se uma curva padrão com concentrações crescentes de solução de glicose a 0,01\%, $(0,0,0015 ; 0,0030 ; 0,0045$; 0,0060; 0,0075; 0,0090; 0,0105 g/100 mL) com leituras em espectrofotômetro a $490 \mathrm{~nm}$ de absorbância. Macêdo et al. (2018) utilizando essa metodologia, obtiveram médias de carboidratos solúveis em Palma forrageira e capim Buffel de 110 e $40 \mathrm{~g} \mathrm{~kg}^{-1} \mathrm{MS}$, respectivamente. Já Santos et al. (2018) trabalhando com sorgo obtiveram 318,2 $\mathrm{g} \mathrm{kg}^{-1} \mathrm{MS}$ de carboidratos solúveis.

\section{CONSIDERAÇÕES FINAIS}

É de extrema importância a qualidade dos carboidratos nas plantas forrageiras, devido estes constituírem a maior fração na constituição dos tecidos da planta, que influencia diretamente na fermentação e motilidade ruminal e consequentemente no desempenho dos animais. Todas metodologias descritas permitem a determinação dos carboidratos, a escolha depende do objetivo e da disponibilidades de materiais.

\section{REFERÊNCIAS}

AGODA-TANDJAWA, G.et al. Properties of cellulose/pectins composites: Implication for structural and mechanical properties of cell wall. Carbohydrate Polymers, v.90, n.2, p.1081$1091,2012$.

ALMEIDA, M. T. C.et al. Predições da espectroscopia no infravermelho próximo podem determinar a digestibilidade e o consumo alimentar de cordeiros confinados. Arquivos

Brasileiro de Medicina Veterinária e Zootecnia, v.70, n.2, p.597-605, 2018.

ALVES, A. R.et al. Fibra para ruminantes: Aspecto nutricional, metodológico e functional. Publicações em Medicina Veterinária e Zootecnia, v.10, n.7, p.568-579, 2016. 
Association of Official Analitycal Chemists - AOAC. Official methods of analysis. 15.ed. Washington D.C., 1990. 1141p.

CABRAL, L. S.et al. Taxas de digestão das frações protéicas e de carboidratos para as silagens de milho e de capim-elefante, o feno de capim-tifton-85 e o farelo de soja. Revista Brasileira de Zootecnia, v.33, n.6, p.1573-1580, 2004.

CAMPOS, F. P.et al. Fiber monosaccharides and digestibility of Milenio grass under N fertilization. Animal Feed Science and Technology, v.183, n.1, p.17-21, 2013.

CAVALCANTI, A. C.et al. Consumo e digestibilidade aparente do feno de Andropogon gayanus colhido em três idades diferentes. Ciência Animal Brasileira, v.17, n.4, p. 482-490, 2016.

CORSATO, C. E.; SCARPARE FILHO, J. A.; SALES, E. C. J. Teores de carboidratos em órgãos lenhosos do caquizeiro em clima tropical. Revista Brasileira de Fruticultura, v. 30, n.2, p. 414 418, 2008.

DETMANN, E.et al. Cinética da degradação ruminal dos carboidratos de quatro gramíneas tropicais em diferentes idades de corte e doses de adubação nitrogenada: Técnica de produção de gases. Revista Brasileira de Zootecnia, v.38, n.1, p.149-158, 2009.

DUBOIS, M.et al. Colorimetric method for determination of sugars and related substances.

Analytical Biochemistry, v.28, n.3, p. 350-356, 1956.

GONÇALVES, L. C.; BORGES, I.; FERREIRA, P. D. S. Alimentação de gado de leite. Belo Horizonte: FEPMVZ, 2009. 412p.

HALL, M. B.et al. A method for partitioning neutral detergentsoluble carbohydrates. Journal of the Science of Food and Agriculture, v.79, n.15, p.2079-2086, 1999.

HURA, T.et al. Different allocation of carbohydrates and phenolics in dehydrated leaves of triticale. Journal of Plant Physiology, v.202, n.1, p.1-9, 2016.

IBÁÑEZ, A. B.; BAUER, S. Downscaled method using glass microfiber filters for the determination of Klason lignin and structural carbohydrates. Biomass and Bioenergy, v.68, n.1, p.75-81, 2014.

KRISHNAMOORTHY, U. C.et al. Nitrogen fractions in selected feedstuffs. Journal of Dairy Scince, v.65, n.2, p.217-225, 1982.

MACEDO JÚNIOR, G. L.et al. Qualidade da fibra para a dieta de ruminantes. Ciência Animal, v.17, n.1, p.7-17, 2007.

MACÊDO, A. J. S.et al. Silages in the form of diet based on spineless cactus and buffelgrass. African Journal of Range \& Forage Science, v.35, n.2, p.121-129, 2018.

MEDEIROS, S. R.; GOMES, R. C.; BUNGENSTAB, D. J. Nutrição de bovinos de corte: fundamentos e aplicações. Embrapa 1.ed. Brasília, DF, 2015. 176p.

MERTENS, D. R. Gravimetric determination of amylase-treated neutral detergent fiber in feeds with refluxing in beakers or crucibles: collaborative study. Journal of AOAC International, v.85, n.6, p.1217-1240, 2002. 
NEGAHDAR, L.; DELIDOVICH, I.; PALKOVITS, R. Aqueous-phase hydrolysis of cellulose and hemicelluloses over molecular acidic catalysts: Insights into the kinetics and reaction mechanism. Applied Catalysis B: Environmental, v.184, n.1, p.285-298, 2016.

NTAIKOU, I.et al. Hydrogen production from sugars and sweet Sorghum biomass using Ruminococcus albus. International Journal of Hydrogen Energy, v.33, n.4, p.1153-1163, 2008.

OLIVEIRA, V. S.et al. Carboidratos fibrosos e não fibrosos na dieta de ruminantes e seus efeitos sobre a microbiota ruminal. Veterinária Notícias, v. 22, n.2, p.1-18, 2016.

PELL, A. N.; SCHOFIELD, P. Computerized monitoring of gas production to measure forage digestion in vitro. Journal of Dairy Science, v.76, n.12, p.1063-1073, 1993.

PEREIRA, E. S.et al. Determinação das frações proteicas e de carboidratos e estimativa do valor energético de forrageiras e subprodutos da agroindústria produzidos no Nordeste Brasileiro.

Semina: Ciências Agrárias, v.31, n.4, p.1079-1094, 2010.

PERETTI, J.et al. Composição química e cinética de degradação ruminal da aveia branca (Avena sativa L.) cv. IPR126 sob diferentes níveis de nitrogênio. Revista Brasileira de Saúde e Produção Animal, v.18, n.1, p.89-102, 2017.

RIBEIRO, L. S. O.et al. Características fermentativas, composição química e fracionamento de carboidratos e proteínas de silagem de capim-elefante emurchecido ou com adição de torta de mamona. Semina: Ciências Agrárias, v.35, n.3, p.1447-1462, 2014.

RIGUEIRA, J. P. S.et al. Níveis de glicerina bruta na ensilagem de cana-de-açúcar: perdas e valor nutricional. Boletim de Indústria Animal, v.74, n.4, p.319-327, 2017.

ROMÃO, C. O.et al. Fracionamento de carboidratos e degradabilidade ruminal da cana-de-açúcar tratada com óxido de cálcio. Arquivos Brasileiro de Medicina Veterinária e Zootecnia, v.65, n.2, p.537-546, 2013.

SÁ, J. F.et al. Fracionamento de carboidratos e proteínas de gramíneas tropicais cortadas em três idades. Arquivos Brasileiro de Medicina Veterinária e Zootecnia, v.62, n.3, p.667-676, 2010.

SALIBA, E. O. S.et al.. Predição da Composição Química do sorgo pela técnica de espectroscopia de refletância no infravermelho próximo. Arquivo Brasileiro de Medicina Veterinária e Zootecnia, v.55, n.3, 2003.

SANTOS, A. P. M.et al. Effects of urea addition on the fermentation of sorghum (Sorghum bicolor) silage. African Journal of Range \& Forage Science, v.35, n.1, p.55-62, 2018.

SCHOFIELD, P.; PITT, R. E.; PELL, A. N. Kinetics of fiber digestion from in vitro gás production. Journal of Dairy Science, v.72, n.11, p.2980-2991, 1994.

SILVA, A. C.; QUEIROZ, D. J. Analise de Alimentos: Métodos químicos e bioquímicos. UFV. 3ed. Viçosa, MG, 2005. 235p.

SILVA, M. R. H.; NEUMANN, M. Fibra efetiva e fibra fisicamente efetiva: Conceitos e importância na nutrição de ruminantes. FAZU em Revista, Uberaba, v.9, n.9, p.69-84, 2012. 
SINGH, S.et al. In vitro ruminal fermentation, protein and carbohydrate fractionation, methane production and prediction of twelve commonly used Indian green forages. Animal Feed Science and Technology, v.178, n.1, p.2-11, 2012.

SLUITER, A.et al. Determination of structural carbohydrates and lignin in biomass.

Laboratory analytical procedure (LAP). Golden, CO: National Renewable Energy Laboratory (NREL); 2012. Disponível em: http://www.nrel.gov/docs/gen/fy13/42618.pdf. Acesso em: 14 jul. de 2017.

SNIFFEN, C. J.et al. Carbohydrate and Protein System for Evaluating Cattle Diets: 11.

Carbohydrate and Protein Availability. Journal of Animal Science, v.70, n.11, p.3562-3577, 1992.

STOKES, S. R.et al. Ruminal digestion and microbial utilization of diets varying in type of carbohydrate and protein. Journal of Dairy Science, v.74, n.3, p.871-876, 1991.

STRADA, E. S. O.et al. Fatty acid composition of beef cattle finished on tropical pasture and supplemented with crude glycerin. Semina: Ciências Agrárias, v.40, n.2, p.993-1000, 2019.

VAN SOEST, P. J. Nutritional Ecology of the Ruminant. Comstock Publ. Assoc. Ithaca, 1994. 476p.

VAN SOEST, P. J; ROBERTSON, J. B.; LEWIS, B. A. Methods for dietary fiber, neutral detergent fiber, and nonstarch polysaccharides in relation to animal nutrition. Journal of Dairy Science, v.74, n.10, p.3597-3597, 1991.

VIANA, P. T.et al. Fracionamento de carboidratos e de proteína das silagens de diferentes forrageiras. Revista Brasileira de Zootecnia, v.41, n.2, p.292-297, 2012.

WANG, J.; YAO, G.; JIN, F. One-pot catalytic conversion of carbohydrates into alkyl lactates with Lewis acids in alcohols. Molecular Catalysis, v.435, n.9, p.82-90, 2017.

ZIKELI, F.; Wheat straw lignin fractionation and characterization aslignin-carbohydrate complexes. Industrial Crops and Products, v.85, n.1, p.309-317, 2016. 